\title{
SOBRE A MUSICALIDADE EM PROSA: MADAME BOVARY DE GUSTAVE FLAUBERT
}

\author{
Elena Gallorini \\ Submetido em 03 de maio de 2019. \\ Aceito para publicação em 08 de julho de 2019.
}

Cadernos do IL, Porto Alegre, n. ${ }^{\circ}$ 58, outubro. p. 177-190.

\section{POLÍTICA DE DIREITO AUTORAL}

Autores que publicam nesta revista concordam com os seguintes termos:

(a) Os autores mantêm os direitos autorais e concedem à revista o direito de primeira publicação, com o trabalho simultaneamente licenciado sob a Creative Commons Attribution License, permitindo o compartilhamento do trabalho com reconhecimento da autoria do trabalho e publicação inicial nesta revista.

(b) Os autores têm autorização para assumir contratos adicionais separadamente, para distribuição não exclusiva da versão do trabalho publicada nesta revista (ex.: publicar em repositório institucional ou como capítulo de livro), com reconhecimento de autoria e publicação inicial nesta revista.

(c) Os autores têm permissão e são estimulados a publicar e distribuir seu trabalho online (ex.: em repositórios institucionais ou na sua página pessoal) a qualquer ponto antes ou durante o processo editorial, já que isso pode gerar alterações produtivas, bem como aumentar o impacto e a citação do trabalho publicado.

(d) Os autores estão conscientes de que a revista não se responsabiliza pela solicitação ou pelo pagamento de direitos autorais referentes às imagens incorporadas ao artigo. A obtenção de autorização para a publicação de imagens, de autoria do próprio autor do artigo ou de terceiros, é de responsabilidade do autor. Por esta razão, para todos os artigos que contenham imagens, o autor deve ter uma autorização do uso da imagem, sem qualquer ônus financeiro para os Cadernos do IL.

\section{POLÍTICA DE ACESSO LIVRE}

Esta revista oferece acesso livre imediato ao seu conteúdo, seguindo o princípio de que disponibilizar gratuitamente o conhecimento científico ao público proporciona sua democratização.

http://seer.ufrgs.br/cadernosdoil/index

Segunda-feira, 07 de outubro de 2019. 


\title{
SOBRE A MUSICALIDADE EM PROSA: MADAME BOVARY DE GUSTAVE FLAUBERT
}

\author{
ABOUT MUSICALITY OF PROSE: MADAME \\ BOVARY BY GUSTAVE FLAUBERT
}

Elena Gallorini*

\begin{abstract}
RESUMO: Este artigo propõe uma análise do ritmo narrativo a partir do romance Madame Bovary, de Gustave Flaubert. Percorrendo a correspondência do autor, evidencia-se que Flaubert manifesta a intenção de revolucionar a linguagem do romance, atribuindo à prosa a musicalidade do verso. Para tal fim, o escritor trabalha febrilmente, escrevendo e reescrevendo as frases até soarem perfeitamente, o que é verificado através da prova do "gueuloir", ou seja a declamação em voz alta. Após destacar as caraterísticas principais do ritmo narrativo dessa obra flaubertiana, examina-se de maneira mais detalhada o capítulo cinco da segunda parte do livro, para determinar quais elementos estilísticos permitem à essa obra, definida pelo mesmo Flaubert como romance de costumes, transformar-se em uma espécie de poema narrativo.
\end{abstract}

PALAVRAS-CHAVE: Madame Bovary; prosa musical; tempo e espaço; ritmo narrativo.

RÉSUMÉ: Cet article propose une analyse du rythme narratif du roman Madame Bovary de Gustave Flaubert. À travers la correspondance de l'auteur, il devient évident que Flaubert manifeste l'intention de révolutionner le langage du roman, en donnant à la prose la musicalité du vers. Dans ce but, l'écrivain travaille fébrilement, écrivant et réécrivant des phrases jusqu'à ce qu'elles sonnent parfaitement, ce qui est confirmé par la preuve du "gueuloir", c'est-à-dire la déclamation à voix haute. Après avoir souligné les principales caractéristiques du rythme narratif de cette ouvre flaubertienne, nous examinons plus en détail le chapitre cinq de la deuxième partie du livre, afin de déterminer quels éléments stylistiques permettent à cette ouvre, définie par le même Flaubert roman de moeurs, de devenir une sorte de poème narratif.

MOTS-CLÉS: Madame Bovary; prose musicale; temps et espace; rythme narratif.

"J'en conçois pourtant un, moi, de style : un style qui serait beau, que quelqu'un fera à quelque jour, dans dix ans ou dans dix siècles, et qui serait rythmé comme le vers [...].

La prose est née d'hier, voilà ce qu'il faut se dire. Le vers est la forme par excellence des littératures anciennes.

Toutes les combinaisons prosodiques ont été faites, mais celles de la prose, tant s'en faut. »

Flaubert, Correspondance.

\section{Introdução}

\footnotetext{
* Doutoranda em literatura francesa na Universidade Federal do Rio Grande do Sul, mestre em literatura europeia e americana pela Università Degli Studi Di Firenze, elenagallorini@gmail.com.
} 
Desde sempre a questão sobre a diferença entre poesia e prosa esteve presente no universo literário, e ainda hoje os estudiosos debatem à procura de caraterísticas que permitam traçar nitidamente a distinção entre esses dois gêneros. Conforme o crítico Tzvetan Todorov, a poesia diferencia-se da prosa pois tem "natureza versificada", enquanto a prosa apresenta uma estrutura mais livre (TODOROV, 1976, p. 385). Entretanto, isso não justificava os poemas escritos em verso livre e os textos em prosa com alto grau de poeticidade.

Hoje em dia, apesar das divergências teóricas, reconhece-se geralmente que a poesia é caracterizada pelo fato de que os aspectos retóricos, quais sejam assonâncias, aliterações, metáforas, o ritmo e a sonoridade, são essenciais à formação do sentido. No entanto, este artigo propõe-se a demostrar que o texto em prosa também apresenta uma forte relação entre forma e conteúdo, uma prosódia, um ritmo narrativo e uma própria sonoridade que podem influenciar a interpretação da obra por parte do leitor.

O romance Madame Bovary de Gustave Flaubert foi definido por Guy de Maupassant como "uma revolução nas Letras" (MAUPASSANT, 1880, p. 46-47). Da mesma maneira, Marcel Proust, no ensaio À propos du style de Flaubert, reconhece a peculiaridade do estilo flaubertiano, definindo as páginas do autor normando um trottoir roulant e algo sem precedentes em literatura (PROUST, 1920, p. 73-74).

Com efeito, o escritor, ao compor a obra, manifesta a intenção de revolucionar a linguagem do romance, atribuindo à prosa a musicalidade do verso. $\mathrm{O}$ presente artigo irá analisar o ritmo narrativo de Madame Bovary para determinar quais caraterísticas permitem a esse texto literário, definido pelo mesmo Flaubert como romance de costumes, transformar-se em uma espécie de poema narrativo.

Para analisar o ritmo do romance serão considerados, em particular, as categorias narratológicas do tempo e do espaço. Quanto ao tempo, é evidente que o ritmo da narrativa está conectado à velocidade de narração. De acordo com a análise narratológica proposta pelo teórico francês Gerard Genette, em um romance é possível distinguir dois tipos de tempo: o tempo da história, ou seja, o tempo em que acontecem os eventos, que se mede em minutos, horas, meses etc.; e o tempo do discurso, cuja unidade são as frases, os parágrafos, as páginas etc. Genette distingue os casos em que o tempo do discurso decorre mais rapidamente em respeito ao tempo da história, como no sumário e na elipse, na mesma velocidade, no caso das cenas, ou mais devagar, como nas pausas descritivas (GENETTE, 1972, p. 129).

Da mesma forma, o ritmo está relacionado com o espaço: a velocidade da narração pode depender do espaço físico e social onde ocorrem os eventos narrados ou do espaço psicológico em que se desenrolam as introspeções das personagens. De qualquer maneira, não se deve esquecer que em um texto existe outro tipo de espacialidade, ou seja, o espaço da linguagem: espaço é página, é parágrafo, é palavra, é pontuação. Assim, a interpretação que o leitor faz de um texto pode ser influenciada pelo número de páginas que formam um capítulo, por quantos parágrafos contém uma página, pela estruturação sintática dos períodos que os compõem e pela maneira com que a pontuação os separa.

\section{A tentação do Flaubert}

A concepção de estilo de Flaubert mudou significativamente ao longo da sua produção literária: pode-se afirmar que, quanto mais escreveu, mais o escritor deu 
importância à forma. Conforme testemunha o mesmo Flaubert na correspondência à amante Louise Colet, ao empreender a redação do romance Madame Bovary, o autor está determinado a compor un livre sur le rien, ou seja, um livro cuja beleza não dependa da história contada, que pode ser definida como um simples fait divers burguês, mas do estilo em que ela é narrada. Conforme as palavras do próprio escritor: "Les oeuvres les plus belles sont celles où il y a le moins de matière; plus l'expression se rapproche de la pensée, plus le mot colle dessus et disparaît, plus c'est beau" (FLAUBERT, 1915, p. 25).

Para tal fim, o autor, inspirando-se na antiguidade, resolve fazer do próprio romance uma prosa em versos, uma espécie de poema narrativo. É o próprio Flaubert quem destaca a importância que detém o ritmo na estruturação da sua prosa. Assim, o escritor afirma:

Vouloir donner à la prose le rythme du vers (en la laissant prose et très prose) et écrire la vie ordinaire comme on écrit l'histoire ou l'épopée (sans dénaturer le sujet) est peut-être une absurdité. Voilà ce que je me demande parfois. Mais c'est peut-être aussi une grande tentative et très originale ! (FLAUBERT, 1980, p. 287).

Flaubert empreende a composição de Madame Bovary após a do romance As Tentações de Santo Antão, do qual o autor compôs uma primeira versão em 1848 e uma segunda em 1874. Inspirando-se pelo homônimo quadro do pintor flamengo Peter Breughel, o autor francês, que passou alguns meses documentando-se sobre o assunto da pintura, escreveu o texto em uma espécie de frenesi romântico. Uma vez terminado o romance, Flaubert convidou os amigos Louis Bouilhet e Maxime Du Camp e o leu para eles durante quatro dias, em busca de um parecer. Bouilhet e Du Camp deram uma opinião fortemente negativa sobre a obra, apontando ao escritor sobretudo o lirismo desmedido da sua prosa. Du Camp afirmou:

Des phrases, des phrases, habilement construites, harmonieuses, souvent redondantes, faites d'images grandioses et de métaphores inattendues, mais rien que des phrases que l'on pouvait transposer sans que l'ensemble du livre en fut modifié. Nulle progression dans, ce long mystère, une seule scène jouée par des personnages divers et qui se reproduit incessamment. Le lyrisme, qui était le fond même de sa nature et de son talent, l'avait si bien emporté qu'il avait perdu terre (DUCAMP, 2002, p. 88).

Isso provavelmente justifica a obsessão pela forma e o trabalho intenso e febril que levou Flaubert nos cinco anos de redação de Madame Bovary: um período em que o autor lutou contra si mesmo, ou melhor, contra a tentação de se deixar levar pelo eflúvio lírico que ele mesmo admitia ser "inerente a sua natureza" (DUCAMP, 2002, p. 90).

Dessa maneira, podia acontecer que o escritor demorasse dias ou até semanas para completar uma página, pois cada frase uma vez escrita passava diversas vezes pela prova do "gueuloir", ou seja, a declamação em voz alta e, caso não a superasse, era reescrita e corrigida inúmeras vezes, até soar perfeitamente. Em um artigo publicado em 1880 no jornal Le Gaulois, Guy de Maupassant afirmava: "Il travaille avec une obstination féroce, écrit, rature, recommence, surcharge les lignes, emplit les marges, trace des mots en travers, et sous la fatigue de son cerveau il geint comme un scieur de long" (MAUPASSANT, 1880, online). 
O escritor Marcel Proust declarou que a partir de Madame Bovary percebe-se o esforço do autor normando para não se deixar levar excessivamente pelo lirismo, se bem que, na sua opinião, Flaubert liberta-se da subjetividade e alcança o seu verdadeiro estilo somente na obra sucessiva, a Educação sentimental (PROUST, 1920, p. 76). Uma tendência contra a qual o autor luta é o excesso de imagens e metáforas que estavam presentes nas frases de As tentações. De acordo com o crítico Albert Thibaudet:

L'image appartient à ce fond de nature qu'il est obligé de refréner et de combattre, elle est l'écume du flot oratoire, et à mesure qu'il se construit contre ce flot, il l'élimine. Ce qu'il en garde lui paraît compassé et il finit par y renoncer complètement (THIBAUDET, 1935, p. 229).

Direcionado por esse objetivo e isolado na sua casa de campo em Croisset, Flaubert transcorreu um febricitante período de composição e correção, como testemunham a copiosa correspondência à Louise Colet e a incalculável quantidade de rasuras e alterações presente nos manuscritos da obra.

\title{
30 ritmo narrativo em Madame Bovary
}

Para analisar o ritmo narrativo na obra Madame Bovary, será primeiramente necessário salientar quais são as caraterísticas relativas ao tempo nessa obra.

Mário Vargas Llosa, no ensaio dedicado a Madame Bovary, destaca a existência de quatro tempos no interior do romance: o tempo singular, ou tempo das ações específicas; o tempo circular, quer dizer, o repetir-se das mesmas ações; o tempo imóvel, as situações em que as personagens não cumprem ações, mas são descritas como objetos; o tempo imaginário, que é constituído por todos os momentos de rêverie durante os quais a personagem figura-se em uma realidade diferente da qual está vivendo (LLOSA, 1979, p. 128-138). O escritor peruano identifica os aspectos específicos de cada tempo, afirmando que o narrador, ao escolher um ou outro tempo, impõe um ritmo diferente ao texto, e evidenciando a importância da sua orquestração. Segundo as palavras de Llosa:

\begin{abstract}
Disse antes que esta estrutura temporal constitui uma unidade indestrutível. Quer dizer, o fundamental não é a existência destes quatros planos que dá a matéria narrativa diferente velocidade, certeza e naturalidade, senão sua interdependência, as mudanças de um a outro, a maneira como se modificam e complementam. [...] Uma grande orquestra de músicos providos dos melhores instrumentos de nada serviria sem um maestro capaz de organizar esse material e essas disposições (LLOSA, 1979, p. 138).
\end{abstract}

Nesse sentido, Marcel Proust salientou o uso magistral que Flaubert fez dos tempos verbais, sobretudo do imperfeito, que o escritor definiu "éternel" (PROUST, 1920, p. 77). Além disso, Proust evidenciou outras particularidades do estilo do autor normando, entre as quais a colocação insólita dos advérbios e o uso sistemático da conjunção "et", que, de acordo com o crítico, teriam sobretudo um valor rítmico:

La conjonction « et » n'a nullement dans Flaubert l'objet que la grammaire lui assigne. Elle marque une pause dans une mesure rythmique et divise un tableau. C'est comme l'indication qu'une autre partie du tableau commence, 
que la vague refluante, de nouveau, va se reformer (PROUST, 1920, p. 7879).

Na mesma época, Albert Thibaudet analisou os vários modelos de período elaborados pelo autor e destacou as diversas funções do "et" flaubertiano. Segundo o crítico francês, a conjunção pode assumir diversos papéis, sendo principalmente uma ferramenta empregada para fins métricos e prosódicos (THIBAUDET, 1935, p. 265).

O espaço físico é nesse romance um elemento fundamental, enquanto as descrições não são pausas entre uma ação e a outra, mas um elemento chave do romance que pode influenciar ou mesmo determinar o comportamento e os sentimentos das personagens. Conforme Thibaudet, a descrição do espaço também está em relação com a musicalidade da frase:

\begin{abstract}
Flaubert n'était nullement musicien, et cependant c'est à la musique que nous sommes obligés d'emprunter des analogies pour expliquer sa composition. Un tableau de Flaubert est composé comme une symphonie, et lui-même emploie ce mot lorsqu'il parle de son tableau du comice agricole, le plus étonnant et le plus complet qu'il ait écrit. Le problème consiste pour lui à établir un accord parfait entre la description matérielle et les sentiments des personnages, un équilibre entre les milieux et les âmes. [...] Il n'y a pour lui, à un moment donné, qu'un tableau possible comme il n'y a qu'une phrase possible (THIBAUDET, 1935, p. 230-231).
\end{abstract}

No que diz respeito ao aspecto visual do texto, essa é uma questão que acompanhou Flaubert ao longo de todas as etapas de realização da própria obra. Isso porque o autor considerava a divisão dos parágrafos e das páginas, assim como dos capítulos e da obra na sua totalidade, um veículo de transmissão do sentido. $\mathrm{Na}$ correspondência à Louise Colet o autor afirma:

\begin{abstract}
Je suis bien désireux d'être dans une quinzaine de jours, afin de lire à Bouilhet tout ce commencement de ma deuxième partie (ce qui fera 120 pages, l'oeuvre de dix mois). J'ai peur qu'il n'y ait pas grande proportion, car pour le corps même du roman, pour l'action, pour la passion agissante, il ne me restera guère que 120 à 140 pages, tandis que les préliminaires en auront plus du double (FLAUBERT, 1980, p. 330).
\end{abstract}

Quanto à distribuição dos parágrafos, a estudiosa Stella Mangiapane analisou as versões precedentes à primeira edição do romance e destacou uma intervenção abundante de Flaubert no manuscrito do copista, a fim de restaurar as divisões do manuscrito autoral ou aportar ulteriores modificações (MANGIAPANE, 2012).

Além disso, Flaubert julgava a pontuação essencial para a estruturação do ritmo das frases, visto que determina como é feita a leitura de um texto. Como Maupassant notou:

Quelquefois, jetant dans un grand plat de cuivre oriental, rempli de plumes d'oie soigneusement taillées, la plume qu'il tient à la main, il prend sa feuille de papier, l'élève à la hauteur du regard, et, s'appuyant sur un coude, déclame d'une voix mordante et haute. Il écoute le rythme de sa prose, s'arrête comme pour saisir une sonorité fuyante, combine les tons, éloigne les assonances, dispose les virgules avec science, comme les haltes d'un long chemin : car les arrêts de sa pensée, correspondant aux membres de sa phrase, doivent être en même temps les repos nécessaires à la respiration (MAUPASSANT, 1880, online). 
Mangiapane tentou comparar o manuscrito autoral de Madame Bovary com o do copista, com a versão pré-original da Revue de Paris e com a primeira edição Levy do 1857. Entretanto, de uma versão à outra a pontuação sofreu inúmeras variações, tornando a análise dificilmente realizável.

De qualquer maneira, pode-se afirmar que Flaubert costumava não respeitar as normas de uso de pontuação, mas a empregava de maneira particular, tendo como objetivo construir o sentido do período através do aspecto sonoro e visual das frases. Como reparou a estudiosa italiana:

Conçue par Flaubert en tant qu'unité textuelle dans laquelle les contenus sont véhiculés aussi par le biais d'une sémiotique autre que celle relevant des mots et solidaire de celle-ci, la page, aussi bien celle manuscrite que celle imprimée, a son propre tempo, une cadence visuelle qui se veut le reflet d'un sens, d'une organisation du récit, d'un souffle narratif (MANGIAPANE, 2012, online).

\section{A tentação da Emma}

Para conduzir uma análise detalhada do ritmo narrativo e demostrar o quanto é forte a relação entre forma e conteúdo em Madame Bovary, julgou-se oportuno examinar o quinto capítulo da segunda parte do romance.

O primeiro capítulo dessa sequência relata a mudança de Charles e Emma Bovary para Yonville. Após chegar na pequena cidade, o casal visita o hotel Lion d'or, lugar de encontro de todos os habitantes da aldeia; aqui Emma conhece o jovem escrivão Léon Dupuis, com quem estabelece desde o começo uma relação amistosa. Após dar à luz, Emma confia a própria filha Berta a uma ama e um dia, desejando ver a recém-nascida, encaminha-se sozinha pela estrada quando encontra casualmente Léon, que resolve fazer o trajeto com ela. O capítulo seguinte contém a narração das reuniões habituais dos habitantes de Yonville, durante as quais a amizade entre a senhora Bovary e Léon torna-se sempre mais intensa, chegando a levantar suspeitas e fofocas. Finalmente, no quinto capítulo, Emma mostra-se apaixonada por Léon e tenta lutar contra a tentação do adultério.

Quanto ao tempo da história, os eventos narrados no capítulo ocorrem em uma tarde de fevereiro durante a qual o farmacêutico Homais e seus filhos, Emma, Charles e Léon realizam um passeio a uma fábrica de fiação, situada na periferia de Yonville. Em seguida, há uma alteração de foco narrativo: da primazia de eventos exteriores para a primazia de eventos interiores, relativos ao dilema psíquico da protagonista: conta-se o período da tentação e a virtude da Emma que, baseando-se nas indicações temporais do capítulo seguinte, dura pelo menos de fevereiro até abril.

O tempo do discurso apresenta uma estrutura variada. O capítulo começa e termina com duas frases concisas, com o verbo no pretérito indefinido. A primeira frase do capítulo, "Ce fut un dimanche de février, une après-midi qu'il neigeait" (FLAUBERT, 1877, p. 110), gera uma atmosfera de suspense, sobretudo porque o capítulo precedente termina com um período proléptico que profetiza o amor da Emma por Léon. No entanto, o despertar de expectativas da primeira frase corresponde à desilusão ao fim do capítulo; em um breve diálogo entre a senhora Bovary e a 
doméstica, com uma frase lacônica, Emma representa seu estreito horizonte de tédio e sofrimento:

- Ce sont les nerfs, répondait Emma ; ne lui en parle pas, tu l'affligerais. - Ah ! oui, reprenait Félicité, vous êtes justement comme la Guérine, la fille au père Guérin, le pêcheur du Pollet, que j'ai connue à Dieppe, avant de venir chez vous. Elle était si triste, si triste, [...] Puis, après son mariage, ça lui a passé, dit-on. - Mais, moi, reprenait Emma, c'est après le mariage que ça m'est venu (FLAUBERT, 1877, p. 120).

Encontram-se poucos exemplos de "tempo singular" ao longo do capítulo. Tendo em vista que a descrição predomina sobre a ação, o tempo principalmente empregado nos períodos é o predileto de Flaubert, ou seja, o imperfeito.

No começo do capítulo, a descrição do passeio é resumida em uma frase irônica: "Rien pourtant n'était moins curieux que cette curiosité" (FLAUBERT, 1877, p. 110). Nos parágrafos sucessivos, em que o tempo narrativo permanece bastante estático, há uma alternância entre a descrição da paisagem e os pensamentos da Emma que, aborrecida com a situação, começa a comparar o marido com o amante.

Os pensamentos da senhora Bovary são interrompidos de repente pelo chorar do filho do senhor Homais, para depois recomeçarem mais intensamente à noite, na intimidade do espaço doméstico. Pode-se identificar o tempo do discurso que Llosa define como "tempo estático". Com efeito, as personagens não estão agindo, mas estão posando como modelos para que Emma esboce um retrato delas que uma vez sozinha começará a idealizar. Passa-se aqui do tempo estático ao tempo da idealização típica dos estados de introspeção da personagem:

\footnotetext{
Madame Bovary, le soir, n'alla pas chez ses voisins, et, quand Charles fut parti, lorsqu'elle se sentit seule, le parallèle recommença dans la netteté d'une sensation presque immédiate et avec cet allongement de perspective que le souvenir donne aux objets. Regardant de son lit le feu clair qui brûlait, elle voyait encore, comme là-bas, Léon debout, faisant plier d'une main sa badine et tenant de l'autre Athalie, qui suçait tranquillement un morceau de glace. Elle le trouvait charmant ; elle ne pouvait s'en détacher ; elle se rappela ses autres attitudes en d'autres jours, des phrases qu'il avait dites, le son de sa voix, toute sa personne (FLAUBERT, 1877, p. 112).
}

No dia seguinte, Emma recebe duas visitas: de manhã a do senhor Lhereux, que vem pela primeira vez mostrar-lhe a própria mercadoria, e de noite a de Léon que, como de costume, vem visitar o casal. Aqui o ritmo da narração equivale ao que Genette define como "cena", visto que se trata de um diálogo em que o tempo do discurso corresponde basicamente ao tempo da história. $\mathrm{O}$ narrador adota o mesmo procedimento no parágrafo seguinte, quando Léon sobe até o quarto da senhora Bovary para conversar com ela.

Nota-se que outros diálogos do capítulo são reportados através do discurso indireto, que, de acordo com Proust, é a técnica geralmente preferida por Flaubert, pois dessa maneira os discursos se misturam com as outras partes do texto, tornando o ritmo do período mais fluido (PROUST, 1920, p. 74).

Entretanto, nesses dois casos o narrador, ao escolher o discurso direto, propicia que o leitor se identifique à personagem e sinta as sensações que ela está experimentando naquele momento, sofrendo com/como a Emma as tentações, tanto as materiais do senhor Lhereux, quanto as sentimentais do Léon. No diálogo entre Emma 
o e jovem escrivão, observa-se que a escolha do discurso direto faz com que a disposição gráfica na página também enfatize a concisão e o peso de cada palavra trocada pelas duas personagens:

La conversation fut languissante, madame Bovary l'abandonnant à chaque minute, tandis qu'il demeurait lui-même comme tout embarrassé. Assis sur une chaise basse, près de la cheminée, il faisait tourner dans ses doigts l'étui d'ivoire ; elle poussait son aiguille, ou, de temps à autre, avec son ongle, fronçait les plis de la toile. Elle ne parlait pas ; il se taisait, captivé par son silence, comme il l'eût été par ses paroles.

- Pauvre garçon! pensait-elle.

— En quoi lui déplais-je ? se dEmmandait-il.

Léon, cependant, finit par dire qu'il devait, un de ces jours, aller à Rouen, pour une affaire de son étude.

- Votre abonnement de musique est terminé, dois-je le reprendre ?

— Non, répondit-elle.

- Pourquoi ?

- Parce que....

(FLAUBERT, 1877, p. 116).

Ao diálogo com Léon segue a narração do período ascético da senhora Bovary, que corresponde a um "sumário" e ao que Llosa define como "tempo circular". A descrição de uma atitude da Emma equivale a uma quantidade indefinida de outras atitudes:

Il en fut de même les jours suivants ; ses discours, ses manières, tout changea. On la vit prendre à coeur son ménage, retourner à l'église régulièrement et tenir sa servante avec plus de sévérité. Elle retira Berthe de nourrice. Félicité l'amenait quand il venait des visites, et madame Bovary la déshabillait afin de faire voir ses membres. Elle déclarait adorer les enfants ; c'était sa consolation, sa joie, sa folie, et elle accompagnait ses caresses d'expansions lyriques, qui, à d'autres qu'à des Yonvillais, eussent rappelé la Sachette de Notre-Dame de Paris (FLAUBERT, 1877, p. 116).

Decidida a resistir à tentação do adultério, Emma resolve ser mais atenciosa para com o marido, o que é visível na realização meticulosa das tarefas de mãe e de dona de casa.

Desde seu começo, esse capítulo caracteriza-se pela presença maciça de objetos. Com respeito a isso, Proust notou que, às vezes, a descrição flaubertiana vem substituir a ação e afirma que, em algumas passagens descritivas, os objetos são personificados, virando tão vivos quanto as próprias personagens (PROUST, 1920, p. 76). Durante o passeio à fábrica, o paralelo que Emma estabelece entre Charles e Léon é constituído mais pela comparação das roupas do que pelas caraterísticas morais dos dois homens:

Charles était là. Il avait sa casquette enfoncée sur ses sourcils, et ses deux grosses lèvres tremblotaient, ce qui ajoutait à son visage quelque chose de stupide ; son dos même, son dos tranquille était irritant à voir, et elle y trouvait étalée sur la redingote toute la platitude du personnage. Pendant qu'elle le considérait, goûtant ainsi dans son irritation une sorte de volupté dépravée, Léon s'avança d'un pas. Le froid qui le pâlissait semblait déposer sur sa figure une langueur plus douce; entre sa cravate et son cou, le col de la chemise, un peu lâche, laissait voir la peau [...] (FLAUBERT, 1877, p. 111). 
Conferindo a versão definitiva com o manuscrito autoral, descobre-se que inicialmente a descrição da vestimenta do Charles era mais extensa, envolvendo também a calça e a luva, tendo sido o trecho eliminado, provavelmente, para favorecer o ritmo. Da mesma maneira, nos parágrafos que relatam a rêverie da Emma, o escritor rasurou uma parte considerável de texto em que a personagem imagina estar em um quarto de Paris e no qual enumera os objetos presentes nesse ambiente, terminando o quadro fantástico com a exclamação: “Ah! si j'avais du moins un édredon en duvet de cygne!" (FLAUBERT, f ${ }^{\circ}$ 209). Logo depois, no encontro de Emma com o senhor Lhereux, o narrador desenvolve uma descrição detalhada das mercadorias:

\begin{abstract}
Alors M. Lheureux exhiba délicatement trois écharpes algériennes, plusieurs paquets d'aiguilles anglaises, une paire de pantoufles en paille, et, enfin, quatre coquetiers en coco, ciselés à jour par des forçats. Puis, les deux mains sur la table, le cou tendu, la taille penchée, il suivait, bouche béante, le regard d'Emma, qui se promenait indécis parmi ces marchandises. De temps à autre, comme pour en chasser la poussière, il donnait un coup d'ongle sur la soie des écharpes, dépliées dans toute leur longueur ; et elles frémissaient avec un bruit léger, em faisant, à la lumière verdâtre du crépuscule, scintiller, comme de petites étoiles, les paillettes d'or de leur tissu (FLAUBERT, 1877, p. 113).
\end{abstract}

Quanto à construção da frase, cada substantivo está acompanhado por um adjetivo, o que gera no período um efeito aliterante: com a letra " $r$ " em "echarpes algériennes", o "l" em "aiguilles anglaises", o "p" e o "l" em "une paire de pantoufles en paille" e com o "c" em "coquetiers em coco". A frase seguinte também é estruturada dessa forma: primeiro, a atitude do senhor Lhereux é denotada através de breves sintagmas justapostos, "cou tendu", "taille penchée", "bouche béante"; em seguida, o narrador serve-se de um jogo fonético para descrever o olhar duvidoso da Emma, que flutua "indécis parmi ces marchandises". De maneira análoga, nos parágrafos precedentes, durante a descrição de Léon, identifica-se a repetição das letras "c" e "p": "entre sa cravate et son cou, le col de la chemise, un peu lâche, laissait voir la peau" (FLAUBERT, 1877, p. 111). Em todos os casos examinados, a musicalidade das palavras contribuiu à transmissão do sentido, tornando o objeto mais visível ao leitor e a tentação mais palpável. A escolha por inserir uma quantidade importante de objetos e de descrevê-los mediante efeitos rítmicos parece responder à necessidade de "dar corpo às frases" e pode ser vista também como uma maneira de materializar os sentimentos da personagem; a título de exemplo, pode-se notar que, após a descrição dos artigos do senhor Lhereux e do diálogo com Léon, segue a enumeração das roupas de Charles das quais Emma começa a cuidar com uma atenção rigorosa, como se quisesse, dessa maneira, esquecer as tentações experimentadas precedentemente:

Quand Charles rentrait, il trouvait auprès des cendres ses pantoufles à chauffer. Ses gilets maintenant ne manquaient plus de doublure, ni ses chemises de boutons, et même il y avait plaisir à considérer dans l'armoire tous les bonnets de coton rangés par piles égales (FLAUBERT, 1877, p. 116).

Ao resistir às tentações do senhor Lhereux e de Léon, Emma torna-se mais cuidadosa e submissa para com Charles: "Elle ne rechignait plus, comme autrefois, à faire des tours dans le jardin; ce qu'il proposait était toujours consenti, bien qu'elle ne 
devinât pas les volontés auxquelles elle se soumettait sans un murmure" (FLAUBERT, 1877, p. 116-117).

Quanto à estruturação dos períodos, os recursos adotados transformam o monótono dia a dia da Emma em um épico dia de tédio. Assim, nos parágrafos em que o narrador descreve a mudança da senhora Bovary vista pelo exterior, tanto através do olhar do Léon, quanto dos habitantes de Yonville, acumulam-se as frases construídas em ritmo ternário:

\begin{abstract}
Emma maigrit, ses joues pâlirent, sa figure s'allongea. Avec ses bandeaux noirs, ses grands yeux, son nez droit, sa démarche d'oiseau, et toujours silencieuse maintenant, ne semblait-elle pas traverser l'existence en y touchant à peine, et porter au front la vague empreinte de quelque prédestination sublime ? Elle était si triste et si calme, si douce à la fois et si réservée, que l'on se sentait près d'elle pris par un charme glacial, comme l'on frissonne dans les églises sous le parfum des fleurs mêlé au froid des marbres. Les autres même n'échappaient point à cette séduction (FLAUBERT, 1877, p. 117).
\end{abstract}

Logo depois, a virtude dela é quase sacralizada em uma frase que remete ao estilo hagiográfico: "Les bourgeoises admiraient son économie, les clients sa politesse, les pauvres sa charité" (FLAUBERT, 1877, p. 117). Essa frase desvenda a intenção irônica do narrador, intenção que no manuscrito autoral era explicitada pela mesma personagem, durante a rêverie no quarto: "Je les entourerai tous les deux de mon dévouement. je passerai sur la terre, comme un ange. la vie des femmes est un martyre" (FLAUBERT, $\mathrm{f}^{\circ}$ 209).

Dessa forma, a sequência de tentações materiais, tentações carnais e submissão ao marido parece querer indiretamente ecoar os três votos franciscanos: pobreza, castidade e obediência. Entretanto, as qualidades morais da personagem são abruptamente denegadas na alínea sucessiva: à "économie", "politesse" e "charité" opõem-se três sentimentos negativos, ocultamente ressentidos por Emma: "Mais elle était pleine de convoitises, de rage, de haine" (FLAUBERT, 1877, p. 118). Trata-se de enumerações cujos últimos elementos poderiam ter sido separados dos outros pelo "et", mas que foram intencionalmente privados da conjunção para que se formasse uma acumulação dos sentimentos e uma oposição simétrica entre imagem externa/condição interna da personagem, ou seja, entre a senhora Bovary vista pelos outros e por si mesma. No parágrafo seguinte desvenda-se o dramático padecer da Emma:

Léon ne savait pas, lorsqu'il sortait de chez elle désespéré, qu'elle se levait
derrière lui afin de le voir dans la rue. Elle s'inquiétait de ses démarches ;
elle épiait son visage ; elle inventa toute une histoire pour trouver prétexte à
visiter sa chambre. La femme du pharmacien lui semblait bien heureuse de
dormir sous le même toit ; et ses pensées continuellement s'abattaient sur
cette maison, comme les pigeons du Lion d'or qui venaient tremper là, dans
les gouttières, leurs pattes roses et leurs ailes blanches (FLAUBERT, 1877,
p. 117).

Encontram-se aqui dois períodos ternários encaixados, ambos construídos segundo um ritmo in crescendo, pois os últimos segmentos de cada período são mais compridos do que os dois primeiros. O primeiro período ternário, "Elle s'inquiétait de ses démarches ; elle épiait son visage ; elle inventa toute une histoire pour trouver 
prétexte à visiter sa chambre", constitui por sua vez a primeira frase do segundo período, que tem uma segunda frase mais curta, "La femme du pharmacien lui semblait bien heureuse de dormir sous le même toit", e uma última frase, introduzida pelo "et" que amplia o quadro introduzindo uma longa imagem: "et ses pensées continuellement s'abattaient sur cette maison, comme les pigeons du Lion d'or qui venaient tremper là, dans les gouttières, leurs pattes roses et leurs ailes blanches" (FLAUBERT, 1877, p. 117).

Destaca-se que a pontuação contribui para criar a progressão do ritmo. $\mathrm{Na}$ primeira parte, o narrador leva o leitor a atentar para as atitudes da personagem, separadas pelo ponto e vírgula, o que introduz uma pausa e concretiza o peso de cada gesto, enquanto a última, introduzida pelo "et" de movimento, corre mais livremente, assim como os pensamentos da Emma. Em todo o caso, a maioria dos períodos até o final do capítulo apresenta um ritmo ternário ou uma enumeração. Essa orquestração de frases constrói um crescendo que materializa o proliferar de exasperação na alma da Emma, que atinge seu clímax nesse parágrafo, em que, através de vários recursos rítmicos, representa-se toda sorte de aborrecimento e cobiça:

\begin{abstract}
Alors, les appétits de la chair, les convoitises d'argent et les mélancolies de la passion, tout se confondit dans une même souffrance ; - et, au lieu d'en détourner sa pensée, elle l'y attachait davantage, s'excitant à la douleur et en cherchant partout les occasions. Elle s'irritait d'un plat mal servi ou d'une porte entrebâillée, gémissait du velours qu'elle n'avait pas, du bonheur qui lui manquait, de ses rêves trop hauts, de sa maison trop étroite (FLAUBERT, 1877, p. 117).
\end{abstract}

Ao advérbio "alors", destacado do resto da frase pela vírgula, segue, no começo da segunda frase, a conjunção "et", que é isolada e solidificada através do hífen e da vírgula. No último período, o crescendo da intolerância da personagem é representado por meio do aumento progressivo de complementos ao redor dos verbos "s'irritait" e "gémissait".

Comparando a edição definitiva com os fólios do manuscrito autoral, torna-se evidente a intenção do autor de mudar radicalmente seu estilo. Flaubert resolveu rasurar a maioria das imagens que inicialmente colocara nesse capítulo.

Por exemplo, no momento em que Emma resolve ter uma atitude virtuosa e afastar-se de Léon, o sentimento de desolação do jovem escrivão era inicialmente representado por uma série consistente de imagens:

Elle lui parut donc si vertueuse et inaccessible, que toute espérance, même la plus vague, l'abandonna. s'en faire aimer, lui sembla dès lors, une entreprise surhumaine, qque chose d'inouï et de perdu dans les nuages, comme ces montagnes que l'on juge démesurées par l'impuissance où l'on est, d'y pouvoir parvenir. Sa passion, d'ailleurs, n'était point de celles que les difficultés obstacles avivent [flamme

légère, elle se courbait vite sous les vents trop forts, et s'appaisait dans les larmes, comme sous une pluie d'été.] [l'expectativeL'incertitude l'avait rendue patiente, et l'admiration presque désintéressée. il y avait dans son amour plus de respect que d'orgueil, plus d'attendrissement encore encore que de concupiscence, et s'il était à cet âge, où l'on goûte toutes les femmes en une seule femme, il était à l'âge aussi où l'on retrouve celle-là dans toutes les autres. Mais par ce renoncement 
qu'il faisait d'elle, il la plaçait / vis-à-vis de lui-mêmet, en des conditions extraordinaires (FLAUBERT, $\mathrm{f}^{\circ}$ 216).

Percebe-se agora o quanto mais concisa e lapidar é a versão definitiva: "Elle lui parut donc si vertueuse et inaccessible, que toute espérance, même la plus vague, l'abandonna. Mais, par ce renoncement, il la plaçait en des conditions extraordinaires" (FLAUBERT, 1877, p. 117).

Em vez de representar em imagem o que a personagem está sentindo, o autor molda as frases até alcançar a forma e a sonoridade perfeitas e, por consequência, a expressão direta da ideia. Nesse sentido, o escritor Guy de Maupassant notou:

\begin{abstract}
Mille préoccupations l'obsèdent. Il condense quatre pages en dix lignes ; et la joue enflée, le front rouge, tendant ses muscles comme un athlète qui lutte, il se bat désespérément contre l'idée, la saisit, l'étreint, la subjugue, et peu à peu, avec des efforts surhumains, il l'encage, comme une bête captive, dans une forme solide et précise (MAUPASSANT, 1880, online).
\end{abstract}

\title{
5 Considerações finais
}

Após ter analisado a estruturação do ritmo narrativo do quinto capítulo da segunda parte, podemos tirar algumas conclusões a respeito da musicalidade da prosa flaubertiana.

No estudo do capítulo demostrou-se que o ritmo narrativo desenvolvido reproduz o nascimento e a evolução do sofrimento interior da Emma. "Escutando" e percorrendo com o olhar as páginas do começo ao fim, observou-se que o aumentar do aborrecimento da senhora Bovary corresponde visivelmente à multiplicação, na estrutura dos períodos, de ritmos ternários e de enumerações que representam em maneira gráfica e sonora essa caraterística psicológica ressentida pela personagem. Assim, a musicalidade das frases substitui a tendência flaubertiana em expressar os sentimentos das personagens através de imagens, que desde a redação de Madame Bovary o autor tentou reprimir.

O ritmo em que são narrados os eventos, assim como os efeitos obtidos através de assonâncias, aliterações, particulares construções sintáticas, o cuidado na distribuição da pontuação e a estruturação específica da página moldam tanto o aspecto sonoro quanto o aspecto visual do texto, contribuindo para delinear o horizonte semântico dessa experiência de vida que é a escritura flaubertiana e que o crítico Roland Barthes definiu, ad hoc, como uma odisseia (BARTHES, 2002, p. 80).

\section{REFERÊNCIAS}

BARTHES, Roland. Flaubert et la phrase. In: Euvres complètes, nouvelle édition revue, corrigée et présentée par Éric Marty, t. IV, 1972-1976. Paris: Ed. Seuil, 2002.

DUCAMP, Maxime. Souvenirs Littéraires: Flaubert, Fromentin, Gautier, Musset, Nerval, Sand. Bruxelles: Editions Complexe, 2002.

FLAUBERT, Gustave. Madame Bovary. Paris: Charpentier, 1877. 
. Pensées de Gustave Flaubert. Texte établi par Caroline Franklin Grout. Paris: Louis Conard, 1915.

Correspondance, t. II, éd. Jean Bruneau. Paris: Gallimard, La Pléiade, 1980.

Correspondance, éd. Jean Bruneau pour les volumes I à IV, et Jean Bruneau et Yvan Leclerc, avec la collaboration de Jean-François Delesalle, Jean-Benoît Guinot et Joëlle Robert pour le volume V, Paris: Gallimard, coll. «Bibliothèque de la Pléiade », 1973-2007.

GENETTE, Gerard. Figures III. Paris: Editions du Seuil, 1972.

LLOSA, Mario Vargas. A orgia perpetua. Flaubert e Madame Bovary. Rio de Janeiro: Francisco Alves editora, 1979.

MANGIAPANE, Stella. Ponctuation et mise en page dans Madame Bovary: les interventions de Flaubert sur le manuscrit du copiste, Flaubert [En ligne], 2012. Disponível em: https://journals.openedition.org/flaubert/1883. Acesso em: 15 nov. 2018.

MAUPASSANT, Guy de. Souvenirs d'un an. Le Gaulois, Paris, 1880. Disponivel em: https://flaubert.univ-rouen.fr/bovary/bovary_6/temoins/guy1.html. Acesso em: 15 nov. 2018.

PROUST, Marcel. À propos du style de Flaubert. La Nouvelle Revue Française, Paris, t. XIV, n' 76, p. $72-90,1920$.

THIBAUDET, Albert. Gustave Flaubert. Paris: Gallimard, 1935.

TODOROV, Tzvetan. Théories de la poésie. Poétique, $\mathrm{n}^{\circ}$ 28. Paris: Éditions du Seuil, 1976. 